\title{
Gömülü Mandibular Üçüncü Molar Dişin Çekimi Sonrası Komşu İinci Molar Dişin Tedavi Gereksiniminin Retrospektif Olarak Değerlendirilmesi
}

\author{
Meltem Özden Yüce(0000-0002-7088-9701) ${ }^{\alpha}$, Gözde Işık(0000-0001-9572-3049) ${ }^{\alpha}$
}

Selcuk Dent J, 2021; 8: 545-552 (Doi: 10.15311/selcukdentj.885273)

Basvuru Tarihi: 23 Subat 202 Yayına Kabul Tarihi: 24 Mart 2021

\section{öz}

Gömülü Mandibular Üçüncü Molar Dişin Çekimi Sonrası Komşu İkinci Molar Dişin Tedavi Gereksiniminin Retrospektif Olarak Değerlendirilmesi

Amaç: Bu çalışmanın amacı, gömülü mandibular üçüncü molar dişin operatif çekimi sonrası komşu ikinci molar dişin periodontal ve/veya endodontik tedavi gereksinimini retrospektif olarak değerlendirmektir.

Gereç ve Yöntemler: Bu retrospektif çalışma, 2018 Ocak ve 2019 Şubat ayları arasında gömülü mandibular üçüncü molar operasyonu için kliniğimize başvurmuş ve tedavileri tamamlanmış hastaların klinik ve radyolojik kayıtları kullanılarak yürütülmüştür. Klinik kayıtlar, fakültenin elektronik arşiv sistemi kullanılarak incelenmiş ve hastaların yaş ve cinsiyeti ile ikinci molar dişe ait tedavi notları kaydedilmiştir. Operasyon öncesi ve operasyon sonrasına ait panoramik radyografilerde sırasıyla Pell-Gregory ve Winter sınıflamasına üçüncü molar dişin anatomik pozisyonu ve ikinci molar dişte gözlenen patolojik bulgular değerlendirilmiştir.

Bulgular: Toplam 1356 hastanın (777 kadın, 579 erkek; ortalama yaş $26.3 \pm 7.4) 7$ 'sinin endodontik ve 185 'inin periodontal tedaviye gereksinim duyduğu gözlenmiştir. Toplam 192 hastanın 5 'i her iki tedaviye de gereksinim duymuş; 135 hastada (\%72.2) kemik kaybı; 36 hastada (\%19.2) periodontal aralıkta genişleme ve 2 hastada (\%1.1) kök rezorpsiyonu gözlenmiştir. Pell-Gregory ve Winter sınıflamalarına göre dişin pozisyonu ile endodontik ve/veya periodontal tedavi gereksinimi arasında istatistiksel olarak anlamlı farkllık bulunmuştur $(p<0.05)$, ancak yaş ve cinsiyet ile tedavi gereksinimi arasında istatistiksel olarak anlamlı farklılık saptanmamıştır $(p>0.05)$.

Sonuç: Çalışmamızda Pell Gregory ve Winter sınıflamasına göre, Sınıf C ve mezyoanguler gömülü üçüncü molarların komşu ikinci molar dişlerin tedavi gereksinimlerini etkilediği gösterilmiştir.

\section{ANAHTAR KELIMELER}

Molar, Diş çekimi, Periodontal, Endodonti

Üçüncü molar dişler, sıklıkla yaşamın ikinci dekatında ve en son süren daimi dişlerdir., ${ }^{1,2} \mathrm{Bu}$ dişler, oral kavitede doğru okluzal pozisyonda sürerek çiğneme fonksiyonuna katılabilir ya da farklı olarak, kısmen sürebilir veya gömülü kalabilirler. $^{3}$ Mandibulada gömülü kalma oranı daha yüksektir ve bu oran, yaş, cinsiyet, kemik mineral yoğunluğu, iskeletsel bozukluk, yetersiz retromolar mesafe gibi oral veya sistemik faktörlere bağlı olarak değişebilmektedir. ${ }^{1}$

\section{ABSTRACT}

Retrospective Assessment of Treatment Requirement of Adjacent Second Molar After Impacted Mandibular Third Molar Extraction

Background: The aim of this study was to retrospectively evaluate periodontal and/or endodontic treatment requirement of the adjacent second molar after extraction of impacted mandibular third molar.

Methods: This retrospective study was conducted on the clinical and radiological records of patients who referred to our clinic for an extraction of mandibular third molar between January 2018 and February 2019. Clinical records were evaluated on the electronic archive system of the faculty, and age and gender of the patients and the treatment notes of the adjacent second molar were recorded. Preoperative and postoperative panoramic radiographs were used for analyze and record of the anatomical position of the third molar and the pathological findings in the adjacent second molar, respectively

Results: Of totally 1356 patients ( 777 women, 579 men; mean age $26.3 \pm 7.4$ ), 7 of them required endodontic treatment and 185 of them required periodontal treatment. Five patients required both of these treatments; bone loss in 135 patients (72.2\%); widened periodontal space in 36 patients $(19.2 \%)$ and root resorption in 2 patients $(1.1 \%)$ were observed. Based on the Pell-Gregory and the Winter classifications, there were statistically significant differences between the position of the tooth and endodontic and/or periodontal treatment requirement $(p<0.05)$. However, no statistically significant difference was found between age and gender of the patient and treatment requirement $(p>0.05)$.

Conclusion: In our study, it was demonstrated that Class $C$ and mesioangular impacted third molars in accordance with PellGregory and Winter classifications were effected the treatment requirements of adjacent second molars.

\section{KEYWORDS}

Molar, Tooth extraction, Periodontal, Endodontics

Gömülü mandibular üçüncü molar dişler, yıllar içinde semptom vermeden kalabilir ancak perikoronit, enfeksiyon, kistik veya neoplazmik oluşuma bağı olarak çekimi gerekebilmektedir. ${ }^{4}$ Bu dişlerin, profilaktik, ortodontik ve protetik nedenlerle veya ilişkili patolojilerin teşhisi amacıyla operatif çekimi, oral ve maksillofasiyal cerrahide en sık uygulanan dentoalveolar prosedürlerden biridir. ${ }^{5}$

Üçüncü molar cerrahisi, komplikasyon riski düşük bir

\footnotetext{
${ }^{\alpha}$ Ege Üniversitesi Diş Hekimliği Fakültesi Ağız, Diş ve Çene Cerrahisi AD. İzmir, Türkiye
} 
prosedürdür ancak, operasyon sırasında veya operasyon sonrası dönemde bazı komplikasyonlar ortaya çıkabilir. ${ }^{6}$ En sık karşılaşılan operasyon sonrası komplikasyonlar; alveolit, enfeksiyon, postoperatif kanama veya inferior alveolar sinir parestezisidir. ${ }^{7,8}$ Bununla birlikte, mandibular üçüncü molar dişlerin \%68.5'inin ikinci molar diş ile yakın ilişkide olduğu ve ikinci molar dişte değişen oranlarda travma oluşumu ile ilişkili olabileceği belirtilmektedir. ${ }^{6,9}$

Travmaya maruz kalan dişlerde, pulpa kanalı obliterasyonu, pulpa nekrozu, internal veya eksternal kök rezorpsiyonu, periodontal kemik veya yumuşak doku kaybı gibi patolojik durumlar rapor edilmiştir. ${ }^{2,6,10}$ Ayrıca, operasyon sonrası dönemde hastalar, çekim yerinde ağrı veya şişlik şikayetiyle kliniğe başvurabilmekte ve bu semptomlar ikinci molar dişte gözlenen travma ile ilişkili olabilmektedir. ${ }^{6}$

Literatürde, ikinci molar dişte dental caries oluşumu ile gömülü üçüncü molar diş arasında pozitif bir korelasyon olduğunu belirten birçok çalışma yayınlanmıştır. ${ }^{2,11}$ Benzer olarak, gömülü üçüncü molar dişlerin, ikinci molar dişte periodontal hastalık gelişimi riskini arttırdığı ve sondalama derinliğinin üçüncü molar dişe komşu ikinci molarlarda iki kat daha yüksek olduğu rapor edilmiştir. ${ }^{10}$ Bu bilgilere ek olarak, gömülü üçüncü molar diş operasyonunu takiben komşu ikinci molar dişlerde, \%20-50 oranında kök rezorpsiyonu bildiren çalışmalar literatürde yer almıştır. ${ }^{3,12}$

Komşu ikinci molar dişlerin periodontal ve endodontik tedavi gereksinimleri, üçüncü molar dişin anatomik pozisyonuna göre değişebilmektedir. Gömülü mandibular üçüncü molar dişin okluzal düzleminin ikinci molar dişin okluzal düzlemine göre seviyesinin esas alındığı Pell-Gregory ${ }^{13}$ vertikal yönde derinlik sınıflamasına göre, Sınıf C kategorisinde bulunan gömülü mandibular dişlerin operatif çekimi, işlem sırasında dişi açığa çıkarmak için var olan kemikten kaldırılan madde miktarının fazla olması nedeniyle daha komplike olarak değerlendirilmektedir. ${ }^{2}$ Bununla birlikte, Winter ${ }^{14}$ sınıflamasına göre mezyoanguler ve horizontal angulasyon gösteren gömülü mandibular üçüncü molar diş çekimi esnasında veya operasyonu takiben komşu ikinci molar dişte travma riskinin daha yüksek olduğu bildirilmiştir. ${ }^{15}$

$\mathrm{Bu}$ bilgiler doğrultusunda, çalışmamızın amacı, gömülü mandibular üçüncü molar dişin operatif çekimi sonrası komşu ikinci molar dişin periodontal ve endodontik tedavi gereksinimlerini retrospektif olarak değerlendirmektir.

\section{GEREÇ VE YÖNTEMLER}

Bu retrospektif çalışmada, 2018 Ocak ve 2019 Şubat ayları arasında Ege Üniversitesi Diş Hekimliği Fakültesi Ağız, Diş ve Çene Cerrahisi Anabilim Dalı'na gömülü mandibular üçüncü molar operasyonu için başvurmuş ve tedavileri tamamlanmış hastaların klinik ve radyolojik kayıtları kullanılmıştır. Çalışmaya, Tıbbi Araştırmalar etik kurulu tarafından onay alındıktan sonra başlanmıştır (20-6.1T/47).

\section{Dahil edilme kriterleri}

1. Çalışmada yer alan araştırmacılar (M.Ö.Y ve G.I) tarafından ve lokal anestezi altında, tek veya çift taraflı gömülü mandibular üçüncü molar dişi operatif olarak çekilmiş,

2. Operasyon öncesine ait en az bir adet panoramik radyografisi bulunan,

3. En az bir yıl klinik ve radyolojik takip verileri bulunan hastalar çalışmaya dahil edilmiştir.

\section{Dışlanma kriterleri}

1. Gömülü mandibular üçüncü molar diş operasyonu öncesi; mandibular ikinci molar dişi endodontik olarak tedavi edilmiş veya çekilmiş,

2. 18 yaş altı ve

3. Kayıtlarında eksik veya hata bulunan hastalar çalışmaya dahil edilmemiştir.

\section{Veri Analizi}

Hastaların demografik (yaş ve cinsiyet), klinik ve radyolojik kayıtları çalışmada yer alan araştırmacılar tarafından retrospektif olarak incelenmiş ve kaydedilmiştir.

Gömülü mandibular üçüncü molar dişlerin çekimi sonrası bu dişlere komşu ikinci molar dişlere uygulanan endodontik ve/veya periodontal tedaviler, hastaların operasyon sonrası ilk bir yıllık dönemine ait panoramik radyografileri ve klinik tedavi kayıtları kullanılarak değerlendirilmiştir. Klinik kayıtlar, fakültenin elektronik arşiv sistemi (DentAssisst ${ }^{\circledR}$, Metasoft Bilgi işlem Hizmetleri, Eskişehir) kullanılarak incelenmiş ve hastaların demografik (yaş ve cinsiyet) bilgileri ile ikinci molar dişe ait tedavi notları kaydedilmiştir. Tedavi edilen ikinci molar dişlerin distal kök yüzeyindeki kemik doku kaybı, periodontal aralıkta genişleme ve internal veya eksternal kök rezorpsiyon bulguları tedavi öncesine ait panoramik radyografiler üzerinde incelenmiş ve kaydedilmiştir.

Gömülü mandibular üçüncü molar dişlerin çekimi sonrası bu dişlere komşu ikinci molar dişlerin endodontik ve/veya periodontal tedavi gereksinimleri ile yaş, cinsiyet ve üçüncü molar dişin anatomik pozisyonu arasındaki ilişki değerlendirilmiştir. Üçüncü molar dişin anatomik pozisyonu, Pell-Gregory ve Winter sınıflamasına uygun olarak ve hastaların operasyon öncesine ait panaromik radyografileri kullanılarak kaydedilmiştir. Pell-Gregory vertikal yönde derinlik sınıflamasına göre gömülü üçüncü molar dişin ikinci molar dişe göre pozisyonu; Sınıf A: Gömülü üçüncü molar dişin okluzal düzlemi ikinci molar dişin okluzal düzlemi ile eşit seviyede, Sınıf B: ikinci molar dişin okluzal düzlemi ve servikal çizgisi arasında, Sınıf C: ikinci molar dişin servikal çizgisinin alt seviyesinde olarak kaydedilmiştir. Winter sınıflamasına göre gömülü üçüncü molar dişin sürme pozisyonu vertikal, horizontal, 
distoanguler ve mezyoanguler olarak değerlendirilmiş ve kaydedilmiştir.

\section{istatistiksel Analiz}

Verilerin tanımlayıcı istatistikleri; ortalama, standart sapma, medyan, minimum, maksimum, frekans ve yüzde değerleri olarak verilmiştir. Nicel verilerin normallik varsayımı Shapiro-Wilk testi ile kontrol edilmiştir. Normal dağılım gösteren değişkenler için Bağımsız örneklem t-testi kullanılmıştır. Kategorik değişkenler arası ilişkiler, Pearson Ki-kare testi ile incelenmiştir.

İstatistiksel analizler IBM SPSS Statistics 25.0 (IBM SPSS Statistics for Windows, Version 25.0. Armonk, NY: IBM Corp.) paket programı kullanılarak yapılmıştır. Tüm analizlerde anlamllık düzeyi 0.05 olarak belirlenmiştir.

\section{BULGULAR}

Bu retrospektif çalışmada, 1580 hasta kaydı içinden; 55'i mandibular ikinci molar dişi endodontik olarak tedavi edilmiş veya çekilmiş; 67'si 18 yaş altı ve 102'si ise radyolojik veya klinik kayitlarında eksiklik nedeniyle değerlendirmeye alınmamıştır. Böylelikle, 2018 Ocak ve 2019 Şubat ayları arasında gömülü mandibular üçüncü molar dişleri operatif olarak çekilmiş 1356 hastanın (777 kadın, 579 erkek; ortalama yaş $26.3 \pm 7.4$ ) klinik ve radyolojik kayıtları değerlendirilmiştir. Hastaların demografik verileri Tablo 1 üzerinde özetlenmiştir.

Tablo 1.

\section{Demografik Özellikler}

\begin{tabular}{|c|c|c|}
\hline & Ort $\pm S S$ & Medyan (Min, Mak) \\
\hline \multirow[t]{2}{*}{ Yaş } & $26.3 \pm 7.4$ & $24(17-64)$ \\
\hline & n & $\%$ \\
\hline \multicolumn{3}{|l|}{ Cinsiyet } \\
\hline Kadın & 777 & 57.3 \\
\hline Erkek & 579 & 42.7 \\
\hline \multicolumn{3}{|c|}{$\begin{array}{l}\text { Pell-Gregory Sinfflamasına göre Dişin } \\
\text { Pozisyonu }\end{array}$} \\
\hline Sinif A & 781 & 57.6 \\
\hline Sinıf B & 419 & 30.9 \\
\hline Sinıf C & 156 & 11.5 \\
\hline \multicolumn{3}{|c|}{ Winter Sınıflamasına göre Dişin Pozisyonu } \\
\hline Vertikal & 410 & 30.2 \\
\hline Horizontal & 203 & 15.0 \\
\hline Mezyoanguler & 562 & 41.4 \\
\hline Distoanguler & 181 & 13.3 \\
\hline \multicolumn{3}{|c|}{ Endodontik Tedavi Gereksinimi } \\
\hline Yok & 1349 & 99.5 \\
\hline Var & 7 & 0.5 \\
\hline \multicolumn{3}{|c|}{ Periodontal Tedavi Gereksinimi } \\
\hline Yok & 1171 & 86.4 \\
\hline Var & 185 & 13.6 \\
\hline
\end{tabular}

SS: Standart Sapma
Gömülü mandibular üçüncü molar dişlerin çekimi sonrası bu dişlere komşu ikinci molar dişlerinde, endodontik $(n=7)$ ve periodontal $(n=185)$ tedaviye gereksinimi olan toplam 192 hastanın 5'i her iki tedaviye de gereksinim duymuştur. Bu 5 hastanın 3'üne kök amputasyonu veya hemiseksiyon uygulanırken 2'sine diş çekimi yapılmıştır. Buna göre, kalan 187 hastanın radyografik incelemesinde, \%72.2'sinde kemik kaybı $(n=135), \% 19.2$ 'sinde periodontal aralıkta genişleme $(n=36)$, \%1.1'inde kök rezorpsiyonu $(n=2)$ görülürken $\% 7.5$ 'inde herhangi bir patolojik bulguya rastlanmamıştır $(n=14)$.

İkinci molar dişlerin endodontik ve/veya periodontal tedavi gereksinimlerinin gömülü mandibular üçüncü molar dişin anatomik pozisyonu ve cinsiyete göre karşılaştırıması Tablo 2 ve Tablo 3'te verilmiştir.

\section{Tablo 2.}

\section{Üçüncü Molar Dişin Anatomik Pozisyonu ve Cinsiyete göre İkinci Molar Dişlerin Endodontik Tedavi Gereksinimleri}

\begin{tabular}{|c|c|c|c|c|c|c|c|}
\hline \multicolumn{8}{|c|}{ Endodontik Tedavi } \\
\hline & \multicolumn{2}{|c|}{ Yok } & \multicolumn{2}{|c|}{ Var } & \multicolumn{2}{|c|}{ Toplam } & \multirow{2}{*}{$p$ değeri } \\
\hline & $n$ & $\%$ & $\mathrm{n}$ & $\%$ & $n$ & $\%$ & \\
\hline \multicolumn{8}{|l|}{$\begin{array}{l}\text { Pell-Gregory } \\
\text { Siniflamasına } \\
\text { göre Dişin } \\
\text { Pozisyonu }\end{array}$} \\
\hline Sinif A & 781 & 57.6 & 0 & 0.0 & 781 & 57.6 & $<0.001$ \\
\hline Sinif B & 418 & 30.8 & 1 & 0.1 & 419 & 30.9 & \\
\hline Sinif C & 150 & 11.1 & 6 & 0.4 & 156 & 11.5 & \\
\hline \multicolumn{8}{|l|}{$\begin{array}{l}\text { Winter } \\
\text { Siniflamasına } \\
\text { göre Dişin } \\
\text { Pozisyonu }\end{array}$} \\
\hline Vertikal & 410 & 30.2 & 0 & 0.0 & 410 & 30.2 & 0.232 \\
\hline Horizontal & 202 & 14.9 & 1 & 0.1 & 203 & 15.0 & \\
\hline Mezyoanguler & 557 & 41.1 & 5 & 0.4 & 562 & 41.4 & \\
\hline Distoanguler & 180 & 13.3 & 1 & 0.1 & 181 & 13.3 & \\
\hline \multicolumn{8}{|l|}{ Cinsiyet } \\
\hline Kadın & 775 & 57.2 & 2 & 0.1 & 777 & 57.3 & 0.144 \\
\hline Erkek & 574 & 42.3 & 5 & 0.4 & 579 & 42.7 & \\
\hline
\end{tabular}


Tablo 3.

\section{Üçüncü Molar Dişin Anatomik Pozisyonu ve Cinsiyete göre İkinci Molar Dişlerin Periodontal Tedavi Gereksinimleri}

\begin{tabular}{|c|c|c|c|c|c|c|c|}
\hline \multicolumn{8}{|c|}{ Periodontal Tedavi } \\
\hline & \multicolumn{2}{|l|}{ Yok } & \multicolumn{2}{|l|}{ Var } & \multicolumn{2}{|c|}{ Toplam } & \multirow{2}{*}{$\underset{\text { değeri }}{p}$} \\
\hline & $\mathrm{n}$ & $\%$ & $\mathrm{n}$ & $\%$ & $\mathrm{n}$ & $\%$ & \\
\hline \multicolumn{8}{|l|}{$\begin{array}{l}\text { Pell-Gregory } \\
\text { Sınıflamasına } \\
\text { göre Dişin } \\
\text { Pozisyonu }\end{array}$} \\
\hline Sinif A & 739 & 54.5 & 42 & 3.1 & 781 & 57.6 & $<0.001$ \\
\hline Sinif B & 350 & 25.8 & 69 & 5.1 & 419 & 30.9 & \\
\hline Sinif C & 82 & 6.0 & 74 & 5.5 & 156 & 11.5 & \\
\hline \multicolumn{8}{|l|}{$\begin{array}{l}\text { Winter } \\
\text { Siniflamasına } \\
\text { göre Dişin } \\
\text { Pozisyonu }\end{array}$} \\
\hline Vertikal & 407 & 30.0 & 3 & 0.2 & 410 & 30.2 & $<0.001$ \\
\hline Horizontal & 143 & 10.05 & 60 & 4.4 & 203 & 15.0 & \\
\hline Mezyoanguler & 446 & 32.9 & 116 & 8.6 & 562 & 41.4 & \\
\hline Distoanguler & 175 & 12.9 & 6 & 0.4 & 181 & 13.3 & \\
\hline \multicolumn{8}{|l|}{ Cinsiyet } \\
\hline Kadın & 675 & 49.8 & 102 & 7.5 & 777 & 57.3 & 0.522 \\
\hline Erkek & 496 & 36.6 & 83 & 6.1 & 579 & 42.7 & \\
\hline
\end{tabular}

Buna göre Pell-Gregory ve Winter sınıflamalarına göre dişin pozisyonu ile endodontik ve/veya periodontal tedavi gereksinimi arasında istatistiksel olarak anlamlı farklılık bulunmuştur $(p<0.05)$. Pell-Gregory Sınıf $A$ pozisyonundaki gömülü mandibular üçüncü molar dişlerin çekimi sonrası bu dişlere komşu olan ikinci molar dişlerin postoperatif periodontal probleminin daha az olduğu, buna karşılık mezyoanguler pozisyonda olan gömülü mandibular üçüncü molar dişlerin çekimi sonrası bu dişlere komşu ikinci molar dişlerin daha fazla periodontal tedaviye gereksinim duyduğu saptanmıştır. Diğer taraftan cinsiyete göre endodontik ve/veya periodontal tedavi gereksinimi incelendiğinde aralarında istatistiksel olarak anlamlı farklılık saptanmamıştır ( $p>0.05)$. Endodontik ve/veya periodontal tedavi gereksiniminin yaşa göre değişip değişmediği değerlendirildiğinde istatistiksel olarak anlamlı farklıı̆̆ın bulunmadığı belirlenmiştir ( $p>0.05$; Tablo 4).

Tablo 4.

Yaşa göre İkinci Molar Dişlerin Endodontik ve Periodontal Tedavi Gereksinimleri

\begin{tabular}{|c|c|c|c|c|}
\hline \multicolumn{5}{|c|}{ Yaş } \\
\hline & $\mathrm{n}$ & Ort $\pm S S$ & $\mathrm{t}$ & $p$ değer \\
\hline \multicolumn{5}{|c|}{ Endodontik Tedavi } \\
\hline Yok & 1349 & $26.3 \pm 7.4$ & -0.054 & \multirow{2}{*}{0.957} \\
\hline Var & 7 & $26.4 \pm 3.9$ & & \\
\hline \multicolumn{5}{|c|}{ Periodontal Tedavi } \\
\hline Yok & 1171 & $26.1 \pm 7.2$ & -1831 & \multirow{2}{*}{0.068} \\
\hline Var & 185 & $27.3 \pm 8.5$ & & \\
\hline
\end{tabular}

SS: Standart Sapma

\section{TARTIŞMA}

Maksiller ve mandibular üçüncü molar dişlerin operatif çekimi Ağız, Diş ve Çene Cerrahisi Anabilim Dalı'nda terapötik ya da profilaktik sebeplerle sıklıkla gerçekleştirilen cerrahi işlemlerdir. Ancak, bu dişlerin operatif çekimi, kısa ve uzun dönemde birtakım komplikasyonlara sebep olabilmektedir. Bu komplikasyonlar arasında, gömülü üçüncü molar dişin cerrahi çekimi sırasında komşu ikinci molar dişin iatrojenik sublüksasyon yaralanmaları ile ikinci molar dişin distalinde var olan ve/veya sonradan meydana gelen semptomatik/asemptomatik periodontal lezyonlar, ilgili ikinci molar dişin prognozunda önemli bir rol oynamaktadır. ${ }^{6,10}$

Her iki çenede de üçüncü molar dişin en sık gömülü kalma sebebi, çenelerde yeterli mesafenin bulunmamasıdır. ${ }^{16}$ Ancak, maksiller tüberositenin uzamış büyüme süresi ve maksiller dentisyonun daha fazla mezyalizasyonu nedeniyle maksiller üçüncü molar dişler mandibular üçüncü molar dişler ile kıyaslandığında bukkal erüpsiyon için daha fazla mesafeye sahiptirler. Bu nedenle, maksillada mandibulaya oranla retansiyon ile daha az sıklıkla karşılaşılmaktadır. ${ }^{15,17} \mathrm{Bu}$ durumla ilişkili olarak araştırmacılar, mandibulada üçüncü molar dişten kaynaklı eksternal kök rezorpsiyonunun maksillaya göre daha yüksek oranda olduğunu bildirmişlerdir. ${ }^{13,15}$ Bu bulguların ışığında, mevcut çalışmamızda sadece gömülü mandibular üçüncü molar dişlerin geriye dönük olarak incelenmesine karar verilmiştir.

Gömülü üçüncü molar dişler sagittal pozisyonlarına göre mezyoanguler, distoanguler, vertikal ve horizontal olarak sınıflandırılmaktadır. ${ }^{14}$ Literatürde, gömülü üçüncü molar diş vakalarının büyük bir kısmında, gömülü üçüncü molar dişin kronu ile komşu ikinci molar diş arasında yakın kontak bulunduğu ve bu durumun ikinci molar dişin distalinde caries, periodontal defekt ve eksternal kök rezorbsiyonuna sebep olabildiği bildirilmiştir. ${ }^{6,11,15}$ Birçok araştırmacı gömülü üçüncü molar dişin pozisyonun distal caries oluşumunda etkisini değerlendirmiş ve mezyoanguler pozisyonda bu komplikasyonun daha sık görüldüğünü belirtmiştir. ${ }^{2,11}$ Allen ve arkadaşları ${ }^{18}$ mezyoanguler konumdaki gömülü üçüncü molar dişlerin, diğer angulasyon tipleri ile karşılaştırıldığında, ikinci molar dişte caries oluşturma riskinin 9.4 kat fazla olduğunu bildirmişlerdir. Bununla birlikte, mezyoanguler ve horizontal pozisyondaki gömülü üçüncü molar dişlerin diğer pozisyonlara göre komşu ikinci molar dişte marjinal kemik kaybı ve kök rezorbsiyonuna neden olma oranının daha fazla olduğu literatürde raporlanmıştır. ${ }^{3,6}$ Çalışmamızda, literatürle uyumlu olarak, mezyoanguler pozisyonda bulunan gömülü mandibular üçüncü molar dişlere komşu ikinci molar dişlerin operasyonu takip eden 1 yıllık dönemde endodontik ve periodontal tedavi gereksiniminin diğer pozisyonlara göre fazla olduğu tespit edilmiştir. 
Nadiren, üçüncü molar diş çekimi uygulanmış hastalar, geç postoperatif dönemde çekim bölgesinde ağrı ve şişlik nedeni ile kliniğe başvurmaktadır ve bu semptomlar ikinci molar diş ile ilişkili olabilmektedir. Üçüncü molar dişin travmatik çekimi, sağlıklı ikinci molar dişte pulpa nekrozu ve internal kök rezorbsiyonu gibi pulpal komplikasyonlara neden olabilmektedir. ${ }^{6}$ Operasyon sırasında komşu dişe fazla ve kontrolsüz kuvvet uygulanması komşu dişte periodontal ligamentte hasara neden olabilmektedir; ek olarak apikal nörovasküler bölgenin de etkilenmesiyle pulpa değişen derecelerde etkilenmektedir. ${ }^{19}$ Kemiğin elastisitesinin azalmış olması, periodontal aralığın daralmış olması ve artmış ankiloz potansiyeli nedeni ile, ileri yaş travmatik çekimler için predispozan bir faktör olarak değerlendirilmektedir. ${ }^{20}$ İatrojenik nedenlerle endodontik tedaviye gereksinimi olan ikinci molar dişlerin yanısıra; klinik ve radyolojik olarak işlemden önce tespit edilememiş olan baskı tipi ile eksternal kök rezorpsiyonuna bağlı olarak üçüncü molar diş çekimi sonrası ikinci molar dişlerde pulpitis ve periapikal enflamasyon gibi endodontik semptomlar meydana gelebilmektedir. ${ }^{15}$ Pulpaya ulaşmamış eksternal kök rezorbsiyonu genellikle asemptomatik olup, klinik olarak tespit edilmesi zordur. $^{21}$ Oenning ve arkadaşları ${ }^{13}$ yapmış oldukları çalışmalarında, konik ışınlı bilgisayarlı tomografinin (KIBT), ekternal kök rezorpsiyonunu saptamada panoramik radyografiden 4.3 kat daha etkili olduğunu bildirmişlerdir. Ancak, herhangi bir ek klinik semptomu bulunmayan dişlerde rutin KIBT çekimi profilaktik değerlendirme için etik değildir; literatürde ikinci molar dişte eksternal kök rezorpsiyonu oluşumu için yüksek risk olarak değerlendirilen mezyoanguler ve horizontal pozisyonda bulunan üçüncü molar dişler işlem öncesi dikkatli bir şekilde değerlendirilmeli ve şüpheli bulunan vakalar ileri inceleme için KIBT tetkikine gönderilmelidir. ${ }^{15,22}$ Çalışmamızda sadece 7 hastada gömülü mandibular üçüncü molar diş çekimini takiben ikinci molar dişte endodontik tedavi gereksinimi gözlenmiştir; ve literatürle uyumlu olarak 5 tanesine komşu olan üçüncü molar diş mezyoanguler pozisyondadır.

Araştırmacılar, uzun yıllardır asemptomatik üçüncü molar diş ile ikinci molar dişi etkileyen periodontal hastalık arasındaki ilişkiyi incelemişler ve ikinci molar dişin periodontal sağlığının korunması için genç erişkinlerde bu dişlerin profilaktik çekimini önermişlerdir.. ${ }^{10,23}$ Yapılan çalışmalar genç hasta populasyonunda, üçüncü molar diş çekiminin ikinci molar dişin periodontal durumunu etkilemediğini belirtmiştir. ${ }^{23}$ Ancak, üçüncü molar diş çekimi sıklıkla ikinci molar dişin distalinde periodontal defektlere neden olmaktadır ve ileri yaştaki, mevcut periodontal hastalığı bulunan hastalarda üçüncü molar dişin çekimi sonrası ikinci molar dişin distalinde derin rezidüel cep oluşumu riski yüksektir. ${ }^{10,23,24}$ illeri yaş periodontal periodontal iyileşme potansiyeli üzerinde negatif etkiye sahiptir; kemik iyileşmesi ve rejenerasyon süreci olumsuz etkilenebilmektedir. ${ }^{25,26}$ Çalışmamızda, retrospektif olarak değerlendirilen hastaların yaş ortalaması 26.3 olup; genç populasyondan oluşan çalışma grubunda yaşa bağlı olarak hastaların periodontal gereksinimlerinin artıp artmaması konusunda istatistiksel olarak anlamlı bir sonuç bulunamamıştır.

Peng ve arkadaşları ${ }^{23}$ yapmış oldukları çalışmalarında, üçüncü molar dişi en az 5 yıl önce çekilmiş olan hastalarda ikinci molar dişin distal cep derinliğinin ve alveoler kemik kaybının dişin mezyalindeki ölçümlerden fazla olduğunu belirtmişlerdir. Üçüncü molar dişlerin mezyoanguler konumda olması ikinci molar diş ile üçüncü molar diş arasında periodontal patojenleri içeren subgingival mikrobiata kolonizasyonunu artırarak bu riski artıran faktörlerdendir. ${ }^{27}$ Çalışmamızda; gömülü mandibular üçüncü molar diş çekimini takiben komşu ikinci molar dişinde periodontal tedaviye gereksinim duyan hastaların \%41.4'ünde üçüncü molar dişin pozisyonu literatürle uyumlu olarak mezyoanguler pozisyondadır.

Cerrahi girişimin zorluk derecesinin saptanabilmesi amacıyla gömülü üçüncü molar dişin derinliğini esas alan Pell-Gregory sınıflaması sık kullanılan kriterlerden biri olup, dişin kemik içerisinde derinliği arttıkça kaldırılan kemik miktarı artacağından Sınıf C dişler, bu sınıflamaya göre zorluk derecesi en fazla olan dişler olarak belirtilmektedir. ${ }^{28}$ Sınıf $C$ üçüncü molar dişlerin operatif çekiminde, komşu ikinci molar dişlerin distalinde uzaklaştırılan kemiğin miktarına bağlı olarak bir kemik defekti oluşmaktadır ve bu durum, ikinci molar dişlerde periodontal problemlere neden olabilmektedir. ${ }^{25,29} \quad$ Literatürle uyumlu olarak çalışmamızda, gömülü mandibular üçüncü molar dişlerin çekimini takiben komşu ikinci molar dişlerin periodontal tedavi gereksinimleri değerlendirildiğinde, oluşan kemik defektinin büyüklüğüne bağlı olarak en çok Pell-Gregory Sınıf C dişlere komşu ikinci molarlarda tedavi ihtiyacı olduğu tespit edilmiştir.

\section{SONUÇ}

Üçüncü molar dişin anatomik pozisyonuna göre cerrahi işlemin zorluk derecesi ve iatrojenik komplikasyonlar açısından cerrahın deneyimi, operasyon sahasına komşu ikinci molar dişin prognozunu önemli ölçüde etkilemektedir. Çalışmamızda; Pell-Gregory vertikal yönde derinlik sınıflamasına göre Sınıf $C$ ve Winter sınıflamasına göre mezyoanguler konumda bulunan dişlerin operasyon sonrası endodontik tedavi gereksinimini etkilediği; yine mezyoanguler konumda bulunan dişin çekimi sonrası ikinci molar dişin periodontal durumunun etkilendiği tespit edilmiştir. Mevcut çalışmanın retrospektif bir çalışma olmasından dolayı, vakalar sadece radyografik veriler ve hastalara ait klinik notlar üzerinden değerlendirilmiştir; hastaların klinik olarak 
değerlendirilememiş olması ve kontrol grubunun olmaması çalışmanın sınırılıklarındandır. Literatürde özellikle yüksek riskli olarak raporlanan mezyoanguler ve horizontal pozisyondaki gömülü mandibular üçüncü molar dişlere komşu ikinci molar dişlerde, daha geniş popülasyonlarda ve uzun dönem takiple yapılacak prospektif çalışmalara intiyaç duyulmaktadır. 


\section{KAYNAKLAR}

1. Altan A, Akbulut N. Does the Angulation of an Impacted Mandibular third Molar Affect thePrevalence of Preoperative Pathoses? J Dent Shiraz Univ Med Sci 2019;20:48-52.

2. Toedtling V, Coulthard P, Thackray G. Distal caries of the second molar in the presence of a mandibular third molar- a prevention protocol. Br Dent J 2016;221:297302.

3. Oenning AC, Freire AR, Rossi AC, Prado FB, Caria PHF, Correr-Sobrinho L, et al. Resorptive potential of impacted mandibular third molars: 3D simulation by finite element analysis. Clin Oral Investig 2018;22:31953203.

4. Polat HB, Ozan F, Kara I, Ozdemir H, Ay S. Prevalence of commonly found pathoses associated with mandibular impacted third molars based on panoramic radiographs in Turkish population. Oral Surg Oral Med Oral Pathol Oral Radiol Endod 2008;105:41-7.

5. Fuster Torres MA, Gargallo Albiol J, Berini Aytés L, Gay Escoda C. Evaluation of the indication for surgical extraction of thirdmolars according to the oral surgeon and the primary caredentist. Experience in the Master of Oral Surgery and Implantology at Barcelona University Dental School. Med Oral Patol Oral Cir Bucal 2008;13:499-504.

6. Oğuz Y, Soydan SS, Onay EO, Cubuk S. Incidence of root canal treatment of second molars following adjacent impacted third molar extraction. J Dent Sci 2016;11:90-4.

7. Andersson L, Andreasen JO. Traumatic dental injuries. In: Andersson L, ed. Oral and Maxillofacial Surgery. West Sussex, UK: Willey-Blackwell, 2010;799-816.

8. Lysell L. Current concept and strategies for third molar surgery. In: Andersson L, ed. Oral and Maxillofacial Surgery. West Sussex, UK: Willey-Blackwell, 2010;195215.

9. Ye ZX, Yang C, Ge J. Adjacent tooth trauma in complicated mandibular third molar surgery: Risk degree classification and digital surgical simulation. Scientific Reports 2016;6:39126.

10.Passarelli PC, Lajolo C, Pasquantonio G, D'Amato G, Docimo $R$, Verdugo $F$, et al. Influence of mandibular third molar surgical extraction on the periodontal status of adjacent second molars. J Periodontol 2019;90:84755.

11.Kang F, Huang C, Sah MK, Jiang B. Effect of Eruption Status of the Mandibular Third Molar on Distal Caries in the Adjacent Second Molar. J Oral Maxillofac Surg 2016;74:684-92.

12. Oenning ACC, Neves FS, Alencar PNB, Prado RF, Groppo FC, Haiter-Neto F. External Root Resorption of the Second Molar Associated with Third Molar Impaction: Comparison of Panoramic Radiography and Cone Beam Computed Tomography. J Oral Maxillofac Surg 2014;72:1444-55.

13. Pell GJ, Gregory BT. Impacted mandibular third molars: classification and modified techniques for removal. Dent Digest 1933;39:330-8.
14. Winter GB. The principles of exodontia as applied to the impacted third molar: a complete treatise on the operative technic with clinical diagnoses and radiographic interpretations. 1th ed. St. Louis: American Medical Book Co; 1926.

15. Smailienè $D$, Trakinienè $G$, Beinorienè $A$, Tutlienè U. Relationship between the Position of Impacted Third Molars and External Root Resorption of Adjacent Second Molars: A Retrospective CBCT Study. Medicina (Kaunas) 2019;55:305.

16.Björg A, Jensen E, Palling M. Mandibular growth and third molar impaction. Acta Odontol Scand.1956;14:231-272.

17. Trakinien e G, Šidlauskas A, Trakinis T, Andriuškevi ciut' e I, Šalomskien 'e L. The Impact of Genetics and Environmental Factors on the Position of the Upper Third Molars. J Oral Maxillofac Surg 2018;76:2271-79.

18. Allen RT, Witherow H, Collyer J, Roper-Hall R, Nazir MA, Mathew G. The mesioangular third molar--to extract or not to extract? Analysis of 776 consecutive third molars. Br Dent J 2009;206:5867.

19.Sigurdsson A, Trope M, Chivian N. The role of endodontics after dental traumatic injuries. In: Hargreaves KM, Cohen S, Berman LH, eds. Cohen's Pathways of the Pulp, 10th ed. St Louis: Mosby Inc., 2011;620-54.

20.Wagner KW, Otten JE, Schoen R, Schmelzeisen R. Pathological mandibular fractures following third molar removal. Int $\mathrm{J}$ Oral Maxillofac Surg 2005;34:722-6.

21.Suter VGA, Rivola $M$, Schriber $M$, Leung $Y Y$, Bornstein MM. Risk factors for root resorption of second molars associated with impacted mandibular third molars. Int J Oral Maxillofac Surg 2019;48:801-9.

22.Li D, Tao Y, Cui M, Zhang W, Zhang X, Hu X. External root resorption in maxillary and mandibular second molars associated with impacted third molars: a cone-beam computed tomographic study. Clin Oral Investig 2019;23:4195-203.

23.Peng KY, Tseng YC, Shen EC, Chiu SC, Fu E, Huang YW. Mandibular second molar periodontal status after third molar extraction. J Periodontol 2001;72:1647-51.

24.Kugelberg CF, Ahlström U, Ericson S, et al. Periodontal healing after impacted lower third molar surgery. A retrospective study. Int $\mathrm{J}$ Oral Surg 1985;14:29-40.

25. Montero J, Mazzaglia G. Effect of removing an impacted mandibular third molar on the periodontal status of the mandibular second molar. J Oral Maxillofac Surg 2011;69:2691-97.

26. Kaminishi RM, Lam PS, Kaminishi KS, Marshall MW, Hochwald DA. A 10-year comparative study of the incidence of third molar removal in the aging population J Oral Maxillofac Sura 2006:64:173-4. 
27. Kan KW, Liu JKS, Lo ECM, Corbet EF, Leung WK. Residual periodontal defects distal to the mandibular second molar 6-36 months after impacted third molar extraction. J Clin Periodontol 2002;29:1004-11.

28. Renton T, Smeeton N, McGurk M. Factors predictive of difficulty of mandibular third molar surgery. Br Dent $\mathrm{J}$ 2001;190:607-10.

29. Kugelberg CF, Ahlström U, Ericson S, Hugoson A, Thilander $H$. The influence of anatomical, pathophysiological and other factors on periodon- tal healing after impacted lower third molar surgery. A multiple regression analysis. J Clin Periodontol 1991;18(1):37-43.

Yazışma Adresi:

Gözde IŞIK

Ege Üniversitesi

Diş Hekimliği Fakültesi

Ağız, Diş ve Çene Cerrahisi AD.

İzmir, Türkiye

Tel : : +902323112809

E Posta: gozdech@hotmail.com 